\title{
How does entrepreneurial orientation affect the business performance of coffee shop MSMEs in Indonesia?
}

\author{
M. Khalifatul Ardhi ${ }^{1}$, Jangkung Handoyo Mulyo ${ }^{2 *}$, and Irham $^{2}$ \\ ${ }^{1}$ Master Students of Agribusiness Management, Department of Agricultural Socio Economics, \\ Faculty of Agriculture, Universitas Gadjah Mada, Indonesia \\ ${ }^{2}$ Department of Agricultural Socio Economics, Faculty of Agriculture, Universitas Gadjah Mada
}

\begin{abstract}
The increasing growth of the coffee shop business with a fast and attractive expansion as a food \& beverage industry in urban areas of Indonesia, especially Special Region of Yogyakarta has led to business competition between micro, small, and medium enterprises (MSMEs) which are required to use their ability to adapt, be competitive and improve business performance. The entrepreneurial orientation is claimed to important contributions to business success. This study aims to analyze the effect of entrepreneurial orientation on business performance. Partial Least Square-Structural Equation Modeling (PLS-SEM) analysis method is used to examine the effect of five dimensions of entrepreneurial orientation (innovative, proactive, risk-taking, autonomy, and competitive aggressiveness) on business performance. This research was conducted at 80 coffee shop MSMEs with the sampling technique using convenience sampling. The results showed that the dimensions of proactive, autonomy, and competitive aggressiveness were found to have a positive and significant effect on business performance, while the innovative and risk-taking dimensions did not affect significantly on business performance.
\end{abstract}

\section{Introduction}

The coffee business is currently an attractive and growing industry and has a broad impact on the Indonesian economy. This is driven by an increase in people's coffee consumption and a shift in consumer preferences for iced coffee drinks as the latest trend with price offers starts at 1.2 U.S. dollars which can be found at local coffee shops. It is possible that local coffee shops have taken over the cafe market in Indonesia [1]. The beginning of the emergence of coffee shop outlets as a business engaged in the food and beverages industry involved the micro, small and medium enterprise (MSMEs) sector as a modern business with strategies and development supported by the use of digital technology.

The increasing growth of the coffee shop business with rapid expansion in recent years is generally located in big cities, one of which is in the Special Region of Yogyakarta. This city is an Indonesian tourist destination, the center of Javanese culture, and is dubbed the city of

\footnotetext{
* Corresponding author: JhandoyoM@ugm.ac.id
} 
education where young people in Indonesia study. They have a new lifestyle to enjoy coffee at the cafe so that the coffee shop business in the area is growing and growing rapidly. This results in intense competition among coffee shop entrepreneurs, so they are required to use their business strategies in order to win the competition and provide maximum satisfaction to their customers.

The growth of MSMEs, especially coffee shops in Yogyakarta, requires the support of reliable human resources to increase productivity and service quality to survive. In addition, they are faced with the problem of limited access to finance and unbalanced competition among coffee shop business actors. Therefore, coffee shop SMEs are required to improve their performance in serving customers through a business strategy known as entrepreneurial orientation. In general, according to $[2,3,4]$ entrepreneurial orientation basically consists of five main dimensions, namely innovative, proactive, risk-taking, competitive aggressiveness, and autonomy.

Furthermore, various kinds of literature state that entrepreneurial orientation (EO) has an important effect on business performance. Studies conducted by [3] state that entrepreneurial orientation can lead companies to develop ideas and realize them, are better able to take risks, find market opportunities and predict the future.

Various studies show the important role of entrepreneurial orientation in influencing business performance in SMEs [5, 6, 7]. On the other hand, coffee shops are classified as businesses operating in the service sector whose entrepreneurial quality is determined by providing satisfactory service to customers. According to $[8,9]$ reveal that EO is very relevant to SMEs engaged in the service sector and has an impact on business performance. This raises the question of how the application of entrepreneurial orientation to MSME coffee shops and its effect on business performance. Therefore, this study was conducted to examine the effect of the five dimensions of EO on the business performance of coffee shop MSMEs in Special Region of Yogyakarta.

\section{Literature and hypotheses}

\subsection{Entrepreneurial orientation}

Entrepreneurial orientation is defined as the processes, practices, and activities used by entrepreneurs in making decisions that lead to the new entry. A new entry is the main process of entrepreneurs in making updates to their business, especially in entering new markets [4]. Furthermore, [10] stated that EO can play a role in the formulation of business strategies that form the basis for entrepreneurial decisions and actions.

The initial concept of EO proposed by $[2,3]$ consists of three dimensions, namely innovative, risk-taking and proactive. The concept was later developed by [4] by adding two other dimensions, namely competitive aggressiveness and autonomy. Innovativeness is a company's tendency to engage in supporting new ideas, novelty, experimentation, and creative processes that can result in new products, services, or technological processes [4]. Proactiveness is described as an opportunity-seeking perspective, looking forward through the introduction of new services and products in competition and acting in anticipation of future demand [10]. Furthermore, risk-taking is a sign of readiness from implementing EO as entrepreneurial behavior by making significant resource commitments to earn high returns by taking opportunities in the existing market. Competitive aggressiveness is a reflection of the company's intense efforts to outperform competitors which are characterized by an aggressive attitude and a strong response to competitors' actions. While autonomy according to [4] is the most important indicator related to the holder of control or the highest authority in decision making. In addition, [4] states that autonomy is the giving of freedom to 
employees to work independently, creatively, pursue opportunities, and fight for new ideas for business performance.

\subsection{Business performance}

Based on the opinion [4] that EO has a different effect on business performance depending on the choice of indicators used. Empirically, [11, 12, 13] emphasizes that objective performance (financial, market share, or profitability) and subjective performance (service quality, customer satisfaction, and employee satisfaction) as the achievement of business performance targets. However, obtaining objective data as a performance measure is a problem in itself so that it is generally considered as information that may be kept confidential to the public [14]. Therefore, this study used subjective performance measures assessment consisting of (sales growth rate, income, customer satisfaction, and employee satisfaction).

\subsection{Entrepreneurial orientation and business performance}

Entrepreneurial orientation (EO) is considered an important concept that can drive business performance through designing new idea-based on knowledge and creating new competencies or redesigning existing competencies so as to encourage creative attitudes within the company [15]. Although there are many successful studies on the implementation of EO in developed countries, the EO research conducted [7] was able to play a role as a determinant of the performance of SMEs in Bangladesh, and [5] revealed a positive and significant relationship between EO and SME performance in India.

Research [16, 17] shows that the three dimensions of EO, namely the innovative, proactive, and risk-taking dimensions have a positive effect on business performance. Meanwhile, [18] stated that only the proactive and innovative dimensions had a significant positive effect on business performance. Different studies were also conducted [19] which showed that only proactive had a positive and significant effect on business performance. Meanwhile, innovation and risk-taking did not significantly affect performance due to the 2009 financial and economic crisis which caused market turbulence. Further, the two dimensions of competitive aggressiveness and autonomy have been used. The results of the study [6] show that proactiveness, risk-taking, and autonomy positively affect performance. Meanwhile, research [7,9] states that only the competitive aggressiveness dimension has no significant effect on performance. Furthermore, [5] found that the two dimensions of competitive aggressiveness and autonomy were negatively related to business performance.

Based on previous research, the following hypothesis is proposed :

$\mathrm{H} 1$ : Innovativeness dimension of EO affects business performance positively.

H2 : Proactiveness dimension of EO affects business performance positively.

H3 : Risk taking dimension of EO affects business performance positively.

H4 : Competitive aggressiveness dimension of EO affects business performance positively.

H5 : Autonomy dimension of EO affects business performance positively.

\section{Materials and methods}

The population of this study was all owners/managers of MSME coffee shops in the Special Region of Yogyakarta. This study used the convenience sampling method for sampling. A total of one hundred and twenty (120) questionnaires have been distributed to MSME coffee shops. However, only eighty (80) owners or managers responded to the survey questionnaire and met the criteria set by the researcher to was declared valid for this study. The questionnaire was designed on a 5-point Likert scale ranging from $1=$ strongly disagree to 5 
$=$ strongly agree which was used to measure 10 items of entrepreneurial orientation (EO) and 4 items of business performance. PLS-SEM (Partial Least Square-Structural Equation Model) analysis is the main tool used to predict the analysis between constructs built. This study uses an exploratory research design approach, therefore the step of using PLS-SEM is oriented to developing theory in exploratory research [20].

\section{Analysis and results}

\subsection{Measurement model analysis}

The first stage of the PLS-SEM analysis is to evaluate the measurement model analysis through the assessment of validity and reliability which consists of; convergent validity, discriminant validity composite reliability. The convergent validity test of the reflective indicators can be seen from the loading factor value for all construct items which must be more than 0.70 . However, values between $0.60-0.70$ still meet the requirements according to the recommendations for exploratory research. Another assessment can be seen from the value of Average variance extract (AVE) which must be greater than 0.50 [21].

The test results in table 1 show that the overall item loading factor value exceeds 0.60 which ranges from (0.639) to (0.893). The AVE values of all variables also met the requirements and were able to explain the average of more than half the variance of the items. Regarding reliability testing on constructs, it is recommended that parameter estimates with composite reliability be used with a minimum value of 0.70 [22]. It is indicated by the variation of the $\mathrm{CR}$ value for all variables between $(0.738)$ to $(0.847)$ so that the reliability value is higher than certain.

Table 1. Convergent validity and factor loadings \& reliability

\begin{tabular}{|l|c|c|c|}
\hline \multicolumn{1}{|c|}{ Variables and items } & $\begin{array}{c}\text { Factor } \\
\text { loadings }\end{array}$ & AVE & CR \\
\hline Innovativeness & & 0.695 & 0.820 \\
\hline Inno1- (we have a business identity with an independent and attractive concept) & 0.811 & & \\
\hline Inno2 - (we actively do something/new method to deal with business problems) & 0.856 & & \\
\hline Proactiveness & & 0.640 & 0.780 \\
\hline $\begin{array}{l}\text { Proact1 - (we are reactive or proactive monitor market trends and create } \\
\text { business opportunities) }\end{array}$ & 0.793 & & \\
\hline Proact2 - (we strive to have intense interactions with consumers) & 0.807 & & \\
\hline Risk-taking & & 0.603 & 0.748 \\
\hline $\begin{array}{l}\text { Risk-tak1 - (we dare to take business decisions without waiting for competitors } \\
\text { to move) }\end{array}$ & 0.893 & & \\
\hline Risk-tak2 - (we dare to invest in quality equipment and outlet support facilities) & 0.639 & & \\
\hline Competitive Aggressiveness & & 0.587 & 0.738 \\
\hline Compagg1 - (we strive to be more competitive and aggressive) & 0.832 & & \\
\hline Compagg2 - (we have the advantage of a strategic outlet location) & 0.695 & & \\
\hline Autonomy & & 0.609 & 0.757 \\
\hline Auton1 - (I have autonomous decision making in business) & 0.774 & & \\
\hline $\begin{array}{l}\text { Auton2 - (we support the efforts and contributions of employees who work } \\
\text { autonomously to this business) }\end{array}$ & 0.787 & & \\
\hline Business Performace & & 0.580 & 0.847 \\
\hline BP1 - (average business income level are growing) & 0.746 & & \\
\hline BP2 - (average business sales are growing) & 0.741 & & \\
\hline $\begin{array}{l}\text { BP3 - (our employees are committed to work and have a high spirit in } \\
\text { providing services) }\end{array}$ & 0.795 & & \\
\hline $\begin{array}{l}\text { BP4 - (our customers have a good level of satisfaction with the quality of } \\
\text { products, services and prices offered) }\end{array}$ & 0.764 & & \\
\hline
\end{tabular}


Good discriminant validity shown from the square root of AVE for each construct is greater than the correlation between constructs in the model [22]. Based on table 2 shows that the AVE value of each variable is higher than the correlation value between other variables so that it meets the recommended criteria.

Table 2. Fornell \& Larcker test of discriminant validity

\begin{tabular}{|l|c|c|c|c|c|c|}
\hline Variables & Inno & Proact & Risk-tak & CompAgg & Auton & BP \\
\hline Inno & $\mathbf{0 . 8 3 4}$ & & & & & \\
\hline Proact & 0.430 & $\mathbf{0 . 8 0 0}$ & & & & \\
\hline Risk-tak & 0.373 & 0.370 & $\mathbf{0 . 7 7 7}$ & & & \\
\hline CompAgg & 0.245 & 0.276 & 0.258 & $\mathbf{0 . 7 8 1}$ & & \\
\hline Auton & 0.444 & 0.370 & 0.303 & 0.347 & $\mathbf{0 . 7 6 6}$ & \\
\hline BP & 0.380 & 0.551 & 0.342 & 0.421 & 0.591 & $\mathbf{0 . 7 6 2}$ \\
\hline
\end{tabular}

\subsection{Structural model analysis and hypotheses testing}

The second stage of the PLS-SEM analysis is to assess the structural model with the criteria of the coefficient of determination ( $\mathrm{R}$ square), predictive relevance (Q square), and continued hypothesis testing through the bootstrapping method on PLS-SEM [20].

\subsubsection{Structural model assessment}

The assessment of the structural model begins with the coefficient of determination ( $R$ square) as the predictive power which is shown based on the three levels of the rule of thumb $(0.67,0.33$, and 0.19$)$ as a strong, moderate and weak model [21]. The research findings show $\mathrm{R}$ square $(0.511)$ which means that business performance can be explained by 51.1 percent by the diversity of EO constructs. The next evaluation is the Q square criteria which are classified according to [23] with weak values (0.02), moderate (0.15), and strong (0.35). The calculation results show that the value of $\mathrm{Q}$ square is $(0.235)$ classified as a moderate level of predictive relevance.

\subsubsection{Hypotheses testing}

Hypothesis testing is an advanced stage of model evaluation to confirm the relationship between EO and business performance through bootstrapping procedures. Through the use of software from Smart-PLS 3.3, the results of hypothesis testing from this study have been summarized in table 3 and figure 1 as follows.

Based on table 3, the results of the path coefficient analysis show that there is a positive and significant relationship. Based on five independent variables studied, three dimensions of EO (proactive, competitive aggressiveness, and autonomy) positively affected business performance, while innovation and risk-taking were not significant. Competitive aggressiveness showed the strongest effect on business performance (path coefficient 0.386 and t-statistic 4.124), followed by proactive (path coefficient 0.340 and t-statistic 3.127). There is also a positive relationship between autonomy and business performance (path coefficient 0.178 and t-statistic 1.898). The positive statistical effect shows that the higher the level of proactiveness, competitive aggressiveness, and autonomy, the higher the business performance. Therefore, the hypotheses (H2), (H4), and (H5) are supported or in other words, can be accepted. 
Table 3. Hypothesis testing results

\begin{tabular}{|c|c|c|c|}
\hline Hypothesis & Relationships & $\begin{array}{c}\text { Path } \\
\text { Cofficient }\end{array}$ & Decision \\
\hline H1 & Innovativeness $\rightarrow$ Business Performance & -0.005 & Not Supported \\
\hline H2 & Proactiveness $\rightarrow$ Business Performance & $0.340^{* * *}$ & Supported \\
\hline H3 & Risk-taking $\rightarrow$ Business Performance & 0.065 & Not Supported \\
\hline H4 & Competitive Aggressiveness $\rightarrow$ Business & $0.386^{* * *}$ & Supported \\
\hline H5 & Autonomy $\rightarrow$ Business Performance & $0.178^{*}$ & Supported \\
\hline
\end{tabular}

Note : $* * * \mathrm{p}$ value $<0.001 * *<0.005 *<0.010$

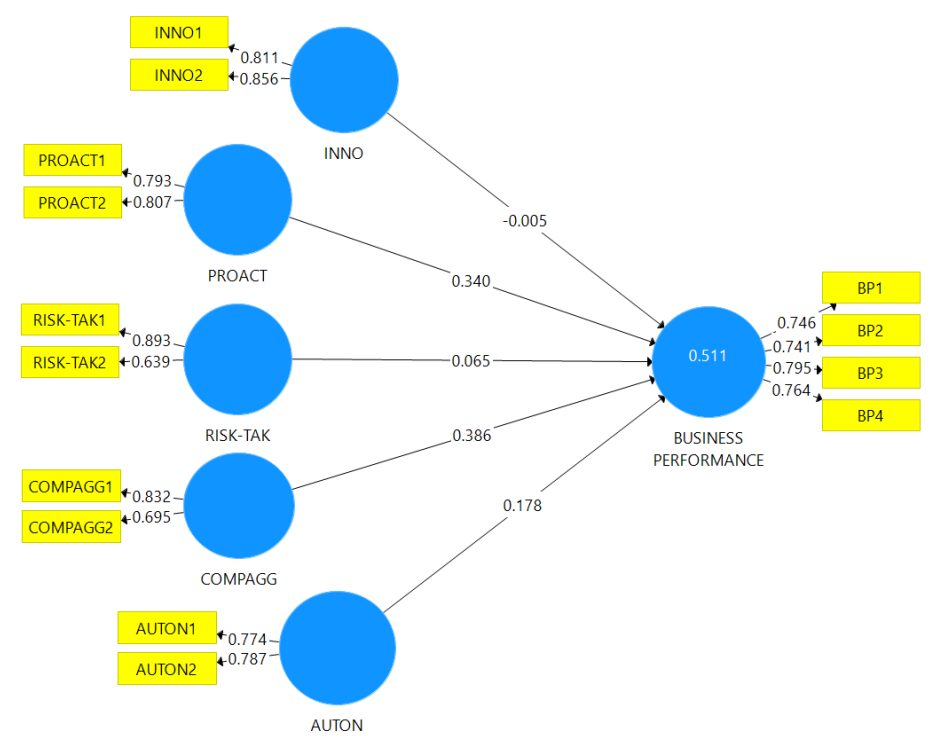

Fig. 1. Partial Least Square-Structural Equation Model Results

\section{Discussion}

\subsection{Innovativeness and business performance}

Based on table 3, the innovative dimension was found to have no significant effect on business performance. The findings of this study are contradicted [5,7,9,17]. A rational explanation of the possible causes is related to the influence of the COVID-19 pandemic which has reduced consumer interest and purchasing power so that it has an impact on business sales even though innovation is carried out. Furthermore, the existence of physical distancing regulations, restrictions on opening hours, and visitor quotas have disrupted business income activities. That is, they must be able to make efforts to adapt to the situation.

Although the COVID-19 pandemic situation is considered the right step to innovate, cost savings to remain operationally efficient have caused business actors to only take policies to tend to survive or delay their totality in innovating. This is because to realize the development of innovations, there will be a high level of risk of failure, limited by R\&D financing and rejection from their employees. Research conducted by [24] found that the negative effects of innovation will be obtained as a result of too many changes for the sake of change resulting in customer dissatisfaction, employee rejection, and increased costs. 
On the other hand, research [6] found that the resolution of business problems that depend on the owner's decision results in minimal innovation that appears to negatively impact business performance. This means, to realize the development of product and service innovation, there will be a high level of failure risk and also limited by R\&D financing and its workforce. Finally, they will be faced with the decision to reorganize by prioritizing the most important and measurable innovation activities such as creating coffee products with attractive bottles for delivery to their customers. However, those who continue to serve at outlets are required to implement COVID-19 of prevention instructions.

\subsection{Proactiveness and business performance}

The proactive dimension shows a significant and positive effect on business performance. Facing the current business environment, a business is required to be able to create business opportunities. It is a way of fulfilling customer needs in market share and customer loyalty [6]. The readiness of business owners to implement business strategies to deal with local and global coffee industry market trends that continue to change to date is proof that they have been proactive and reactive to changing market situations. According to research [16], being proactive will encourage companies to anticipate and act before market changes occur and the direction of existing competition is formed.

Furthermore, the COVID-19 pandemic has forced them to be more intense in interacting with consumers through strategic efforts and meeting the needs of their customers. The number of their customers who choose to do activities at home finally encourages them to only serve orders by delivery. In addition, the rapid development of the use of social media Instagram is increasingly being recognized for its role in encouraging marketing strategies. They also provide contact numbers and strive to be active (content/post creation) as the most effective way to interact with customers. Thus, their proactiveness has an impact on improving business performance.

\subsection{Risk-taking and business performance}

The dimension of risk-taking has no significant effect on business performance. The results of this study are in stark contrast to many previous studies but are in line with research [5, 18]. So, the explanation for why this is happening is first, the main selling product of coffee shops is coffee drinks. However, coffee drinks are considered as a product that is very vulnerable to be imitated by competitors, so there is a tendency to monitor competitors' movements first. In most cases, [6] reveals that the inability to create opportunities is highly dependent on the actions of their managers.

Futhermore, the COVID-19 pandemic as disruption has caused them to face a business situation full of uncertainty. The results of this study are supported by [19] who found that risk-taking in a world crisis has the potential to fail. The COVID-19 pandemic has also made them try to reduce financial spending and be required to be efficient. This means that limited resources also encourage them to adopt competitor strategies to avoid the risks that occur and find it difficult to find new markets. The second reason, risk-taking is measured by the courage to invest in new equipment and facilities related to innovation development activities. Thus, the findings on the previous innovative dimension are followed by the results of the risk-taking dimension on business performance. The courage to invest through immeasurable capital planning will have a negative impact on business expectations or result in financial losses. Thus, the more risks taken will have a negative impact on improving business performance. 


\subsection{Competitive agressiveness and business performance}

Based on the results of the analysis in Table 3, the dimensions of competitive aggressiveness have a significant effect on business performance. The findings of this study are certainly in line with expectations and provide different results from previous studies. Competitive aggressiveness reflects how to engage with competitors, dare to enter the market, and realize strategies faster than competitors. This is a form of their reaction so as not to lose competition so that efforts appear such as the creation of new products, promotions, or equipping facilities as a form of attracting customer interest and maintaining its market segment. Thus, the effort to be more competitive and aggressive is able to improve their business performance.

Based on our observations, the location of each coffee shop tends not to be spread evenly, but many are also close to each other in one area. In this study, a strategic outlet location is an effort to outperform competitors. [6] argue that the level of entrepreneurial orientation will increase and become a determinant of success when businesses are established in urban areas and are involved in the industrial sector. Strategically, being near the center of the crowd will be easily found by consumers and become the closest choice to visit. However, it is not uncommon for those who are not in strategic locations to generally make introduction efforts through social media and direct consumers to visit. This means that when the outlet is in a strategic location, it will further improve business performance.

\subsection{Autonomy and business performance}

The autonomy dimension shows a significant and positive influence on business performance. The results of this study are in line with $[6,7,9]$. This means that the role of the owner or manager is quite autonomous and is needed in leading the organization to improve business performance. This is also due to the fact that most of the owners who started their businesses worked as baristas. That is, they have the capacity or ability to understand the advantages of the product and its business concept. Thus, the higher their autonomous attitude, the more successful owner or managers in holding their control and space to produce new discoveries. In addition, [25] argues that autonomy makes owners or managers leave their comfortable positions and encourages them to seek other ideas for the creation of new ideas.

Furthermore, their autonomous attitude is also shown by providing freedom and opportunities for employees to contribute, for example, the freedom to serve coffee drinks with authentic flavors, improve product quality and provide good service. It can be said that they have succeeded in achieving an attitude of loyalty and encouraging the entrepreneurial spirit of employees. Thus, the practice of autonomy shown individually and in teams is able to have an impact on improving business performance.

\section{Conclusion}

The dimensions of entrepreneurial orientation (EO) that have a significant and positive effect on business performance are the dimensions of proactiveness, competitive aggressiveness and autonomy. Therefore, an increase in these three dimensions will improve business performance. Meanwhile, the innovative and risk-taking dimensions have no significant effect on the business performance of coffee shop MSMEs in Special Region of Yogyakarta. 


\section{References}

1. Statista. URL: https://www.statista.com/statistics/1034500/indonesia-coffee-shopoutlets-number-by-brand/ (2021)

2. Miller, Management Science, 29, 770-791 (1983)

3. Covin J.G., Slevin D.P., Strategic Management Journal, 10 (1989)

4. Lumpkin, G.T., Dess, G.G., Academy of Management Review, 211 (1996)

5. Gupta R., International Journal of Business \& Economics, 181 (2019)

6. Kosa, A., Mohammad, I., Ajibie, D., Journal of Global Entrpreneurship Research, 81 (2018)

7. Ahmed Al Asheq. International Journal Entrepreneurship. World University of Bangladesh, 23, 1 (2019)

8. Benny, H. Asia Pacific Journal of Innovation \& Entrepreneurship, 132 (2019)

9. Abbas, U., I., Martins, M., A., International Journal of Economics \& Finance Issues, 10 2 (2020)

10. Rauch, A., Wiklund, J., Lumpkin, G.T., Frese, M., Entrepreneurship Theory \& Practice, 333 (2009)

11. Venkatraman N, Ramanujam V., Academy of Management Review, 114 (1986)

12. Agarwal, S., Krishna Erramilli, M., \& Dev, C. S., Journal of Serv Marketing, 171 (2003)

13. Lin, C. H., Peng, C. H., \& Kao, D., T., International Journal of Marketing, (2008)

14. Dess, G.G. \& Priem, R.L., Journal of Management Studies, 32 (1995).

15. Choi, S. B. \& Williams, C., Industry \& Innovation, 238 (2016).

16. Hughes, M.; Morgan, R.E., Industrial Marketing Management, 36 (2007)

17. Hsing-Kuo Wang \& Yu-Fang Yen., T.Q.M. \& Business Excellene, 23 (2012)

18. Cho, Y., H., \& J., H., Lee., Sustainability, 124954 (2020)

19. Sascha, K. J. P., Coen, R., Marthew, H., \& Vincent, H., Review of Management Science, 62 (2012)

20. Hair, J.F., Hult, G.T., Ringle, C. M., \& Sarstedt, M., A primer on partial least squares structural equation modelling (PLS-SEM). SAGE Publishing, California (2014)

21. Chin, W. W., The partial least squares approach for structural equation modelling. In G. A. Marcoulides (Ed.), Modern Methods for Business Research 295 2. London: Lawrence Erlbaum Associates, (1998)

22. Fornell, C. \& Larcker, D.F., Journal of Marketing Research, 181 (1981)

23. Hair, J., Hult, G., Ringle, C. \& Sarstedt, M., A Primer on Partial Least Square Structural Equation Modeling (PLS-SEM), Sage, Thousand Oaks, CA, (2017)

24. Simpson, P.M., Siguaw, J.A. \& Enz, C.A. Journal of Business Research, 59 (2006)

25. Coulthard, M., Journal Global of Business \& Technology, 31 (2007) 